CLINICAL SCIENCE

\title{
Value of two mortality assessment techniques for organ cultured corneal endothelium: trypan blue versus TUNEL technique
}

\author{
P Gain, G Thuret, C Chiquet, J M Dumollard, J F Mosnier, C Burillon, B Delbosc, \\ P Hervé, L Campos
}

See end of article for authors' affiliations

\section{Correspondence to:}

Philippe Gain, MD, PhD,

Department of

Ophthalmology, Pavillon

50A, Hôpital Bellevue,

CHU Saint-Etienne, 42055

Saint-Etienne Cedex 2,

France:

philippe.gain@

univ-st-etienne.fr

Accepted for publication 5 October 2001
Background/aim: It is known that trypan blue staining is not a good predictor of loss of corneal endothelial cells (ECs) during organ culture. As it is primarily an indicator of membrane integrity, it would also not be expected to identify ECs undergoing apoptosis. The aim of this study was to determine the ability of the in situ TdT dUTP mediated nick end labelling (TUNEL) technique to detect cell death in the corneal endothelium caused by apoptosis during organ culture, compared with conventional vital staining with trypan blue.

Methods: 31 human corneas were organ cultured at $31^{\circ} \mathrm{C}$ for $3-35$ days. Staurosporine was used to induce apoptosis in five control corneas. The endothelium was assessed by trypan blue and by the in situ TUNEL technique. The percentages of trypan and TUNEL positive ECs were compared. Their links with sex, donor age, time from donor death and organ culture, initial and final EC density and cell loss were studied.

Results: TUNEL stained ECs were observed in all corneas. TUNEL positive ECs were mostly located either in corneal folds or at the periphery of corneal folds showing central shedding. The mean percentage of cell death at the end of storage, assessed by the trypan blue technique, was $1.47 \%$ (SD 2.63, range 0.03-12); assessed by the TUNEL technique it was $12.7 \%$ (SD 16.4 range 0.6-65.5). There was a significant correlation between the two techniques $(r=0.7, p<0.001)$. The percentage of TUNEL stained ECs was correlated negatively with EC density at the end of storage $(r=-0.47, p<0.005)$ and positively with percentage EC loss during storage $(r=0.46, p<0.05)$.

Conclusion: This study demonstrates that organ cultured corneas systematically carry non-viable ECs that are implicated in cell death by apoptosis and go undetected when trypan blue staining is used. Because the in situ TUNEL assay detects earlier events in the cell death process than does trypan blue, it should be used to quantify endothelial viability, especially for experiments with new storage media.
S orage of human corneas before grafting, whether in a $+4^{\circ} \mathrm{C}$ liquid medium or by organ culture, inevitably causes cell death in the endothelium, which reduces endothelial cell (EC) density between the start and end of the storage process. ${ }^{1-3}$ Corneal banks control the viability of the corneal endothelium by cell density measurement, using either specular microscopy, the method most used in the United States, ${ }^{4-7}$ or optical microscopy, the method most used in Europe. ${ }^{89}$ In some banks, including our own, there is a double count: at the very start of storage and just before delivery. This allows measurement of the percentage cell loss during storage. Besides this count, some corneal banks use a technique that identifies cell death by trypan blue staining. ${ }^{9}$ On completion of these endothelial examinations, corneas are generally rejected for grafting if at the end of storage they present an EC density of less than 2000 cells per $\mathrm{mm}^{2}$ (between 1900 and 2200, depending on the bank), and/or considerable cell loss during storage, ranging from $10 \%$ to $20 \%$ depending on the bank. ${ }^{9}$ For banks that use trypan blue staining, the presence of extensive areas of dead cells, or for some banks a dead cell count greater than $2 \%$, are further reasons to reject corneas.

The mechanisms of EC death during organ culture are not yet properly understood, and controversial. ${ }^{10}{ }^{11}$ This EC death may be linked to necrosis or the activation of apoptosis, or to a combination of these. The two phenomena are different in every respect: necrosis occurs accidentally and is accompanied by an adjacent tissue reaction, while apoptosis is a method of controlled, "discreet" elimination of cells. The role of apopto- sis in EC death during storage of human corneas by organ culture, was recently highlighted by Albon et al. ${ }^{10}$ The authors made an adaptation, specific to the study of human corneal endothelium, of the TdT mediated dUTP nick end labelling (TUNEL) technique, ${ }^{12}$ which highlighted the internucleosomial fragmentation of deoxyribonucleic acid (DNA) that is characteristic of apoptosis. The TUNEL technique is not fully specific in the detection of apoptosis compared to necrosis, and depends on the tissue model being studied. ${ }^{13-15}$ But Albon et al confirmed that the TUNEL technique could specifically detect apoptotic cells in the human corneal endothelium. The authors confirmed this specificity by staining nuclei with Hoechst 33345 (bis-benzamide), which reveals chromatin condensation during apoptosis. They also highlighted, by immunohistochemistry, the activation of caspase 3, the apoptosis inducing protease that is responsible for activating the endonucleases that take part in the characteristic fragmentation of nuclear DNA. The in situ TUNEL technique on whole corneas performed by these authors also allowed quantification and localisation of apoptotic cells in the endothelium. Apoptosis was also shown to be implicated in EC death during short term human corneal storage in $+4^{\circ} \mathrm{C}$ liquid medium by Komuro et al. ${ }^{16}$ The authors also used TUNEL, but in their model it was performed on histological cross sections of corneas. More recently Crewe ${ }^{11}$ highlighted, in a far more limited way than Albon, ${ }^{10}$ the expression of activated caspase 3 in immunohistochemistry in the ECs of corneas stored in organ culture at $+34^{\circ} \mathrm{C}$ beyond 28 days, or after more than 5 days in deswelling medium, which is known to be toxic. ${ }^{17}$ 


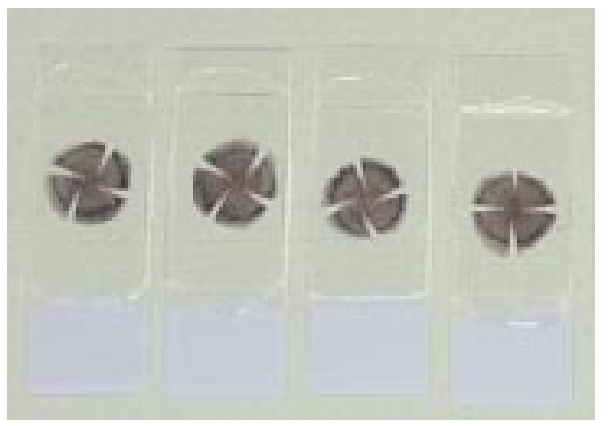

Figure 1 Flat mounting of human corneas. This technique eliminates at least part of the fold related relief, thus facilitating the quantification of positive ECs.

It is a fact that morphological and biochemical changes caused by apoptosis affect only at a very late stage the permeability of cell membranes, be they of nuclei or cytoplasm, ${ }^{18-21}$ but this fact has never been demonstrated with regard to apoptotic corneal endothelium. It is a known fact that trypan blue staining is not a good predictor of loss of cell function. As it is primarily an indicator of membrane integrity, it would also not be expected to identify cells undergoing apoptosis during organ culture given that one of the features of apoptosis is maintenance of plasma membrane integrity, at least until the advanced stages of cell degradation. In this study we wished to compare the ability of TUNEL and trypan blue staining to identify non-viable ECs. The two techniques were performed in immediate succession on human corneas at the end of organ culture storage. The aim was to assess the ability of these two techniques to identify corneas that display considerable cell loss between the start and end of organ culture.

\section{MATERIALS AND METHODS}

\section{Human corneas}

The study was conducted according to the tenets of the Declaration of Helsinki. Thirty four scientific human corneas from seven females and 17 males were obtained from our cornea bank. These corneas were rejected for grafting owing to a medical contraindication involving the donor. Mean donor age was 74 years (SD 15, range 38-93). All corneas were from non-heart beating donors. Corneas were obtained by in situ excision of the corneoscleral button and immediately placed in $50 \mathrm{ml}$ of Inosol medium at $31^{\circ} \mathrm{C}$ (Chauvin-Opsia, Labege, France), except three corneas which were analysed immediately after retrieval without immersion in the storage medium. Mean time from death to preservation was 14 hours (SD 8, range 4-42). For the 31 preserved corneas, storage time varied from 3-35 days (mean 20 (SD 10) days). When storage duration exceeded 14 days, the organ culture medium was renewed. Endothelial cell density in 19 corneas was determined at the start of storage (between 2 and 4 days) and in the final days of storage. Corneas stored for less than 8 days $(\mathrm{n}=$ 12) only underwent the final count. Cell density was established after dilatation of the intercellular spaces with 0.9\% sodium chloride (Unilarm, Ciba Vision Ophthalmics, Toulouse, France) for 4 minutes, under light microscopy, at the time of trypan blue staining (see below). An automated analyser allowed measurement of cell density from three microphotographs obtained randomly in the $8 \mathrm{~mm}$ central zone of the cornea and taking account of at least 300 cells. ${ }^{22}$

\section{Trypan blue staining and the in situ TUNEL technique}

The mortality rate of ECs was assessed in each cornea at the end of storage, after vital staining using trypan blue ( Sigma, St Louis, MO, USA). Three hundred $\mu \mathrm{l}$ of $0.4 \%$ trypan blue (Sigma) were put on the endothelial side of the cornea and

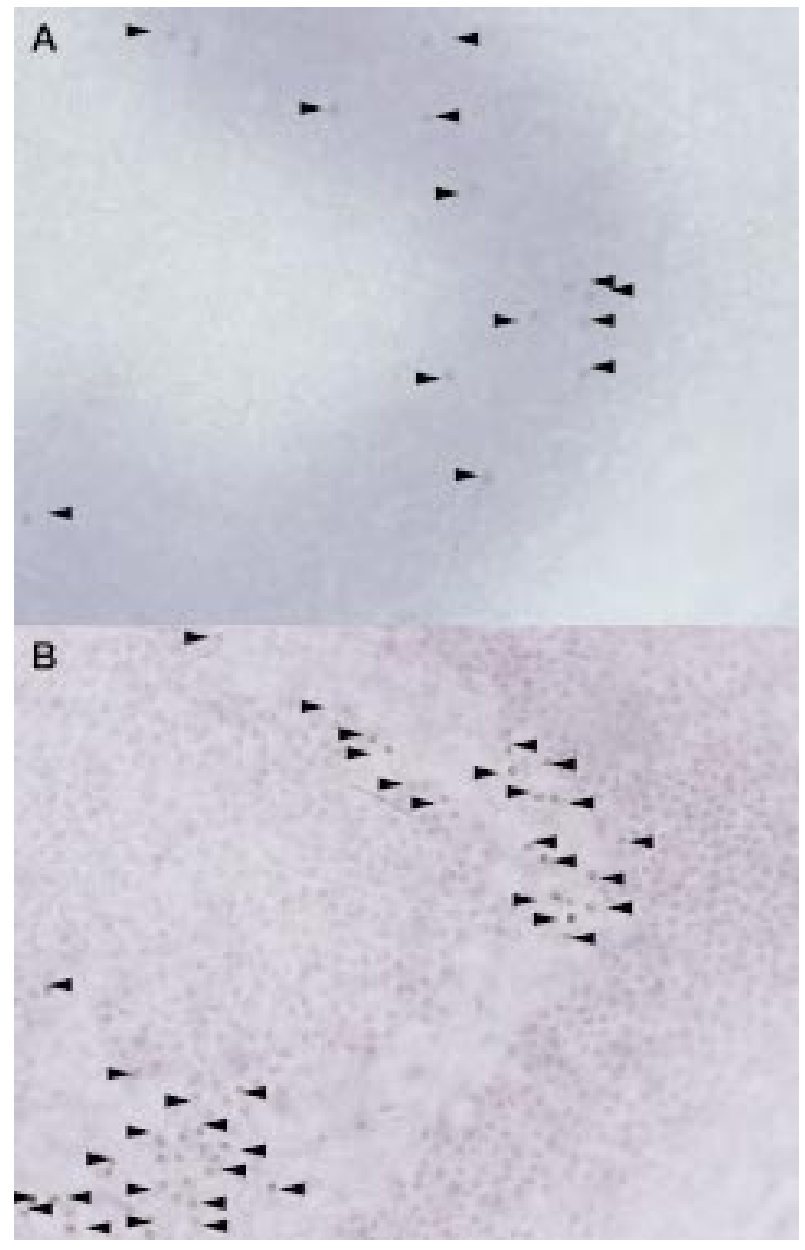

Figure 2 Dual labelling of the same corneal fold by vital staining with trypan blue (A), then by the TUNEL technique (B). Note that the number of TUNEL positive cells is higher. Counterstaining of the nuclei with haematoxylin (B) ( $\times 10$ magnification).

incubated for 90 seconds at room temperature. The mortality was calculated using an analyser, after pointing with the mouse at the blue stained nuclei on each zone studied.

Immediately after the trypan blue count, corneas were fixed for 24 hours in $10 \%$ formaldehyde in phosphate buffered saline (PBS) at room temperature. The TUNEL assay was performed using reagent from the in situ cell death detection kit (Boehringer, Mannheim, Germany) and according to Gavrieli's method, ${ }^{12}$ taking account of the adaptations described by Albon et $a l^{10}$ which permit study of the whole corneal endothelium. After two rinses in PBS, corneas were incubated with $2 \%$ hydrogen peroxide in PBS for 20 minutes to quench endogenous peroxide, then rinsed three times in PBS and pretreated with proteinase $\mathrm{K}(20 \mathrm{mg} / \mathrm{ml}$ in PBS $)$ for 30 minutes (Boehringer, Mannheim, Germany). Corneas were washed twice in PBS and incubated with $0.1 \%$ Triton X-100 (Sigma) for 20 minutes. After three rinses in PBS, the endothelial side was incubated for 2 hours at $37^{\circ} \mathrm{C}$ in a moist chamber with the TUNEL mixture $(5 \mu \mathrm{l}$ of TdT $+45 \mu \mathrm{l}$ of fluorescein conjugated dUTP). After three rinses in PBS, the endothelial side was incubated with peroxidase conjugated antifluorescein antibody for 1 hour at $37^{\circ} \mathrm{C}$. After three rinses in $\mathrm{PBS}$, di-amino-benzidine (DAB) (Sigma) was applied on the endothelium at RT. Nuclei were counterstained by 45 seconds of incubation with Meyer haematoxylin (Sigma) followed by a 10 minute rinse in PBS. For each assay, a negative control was performed on one cornea, omitting TdT. An original protocol was used to carry out a permanent flat mounting of the whole 


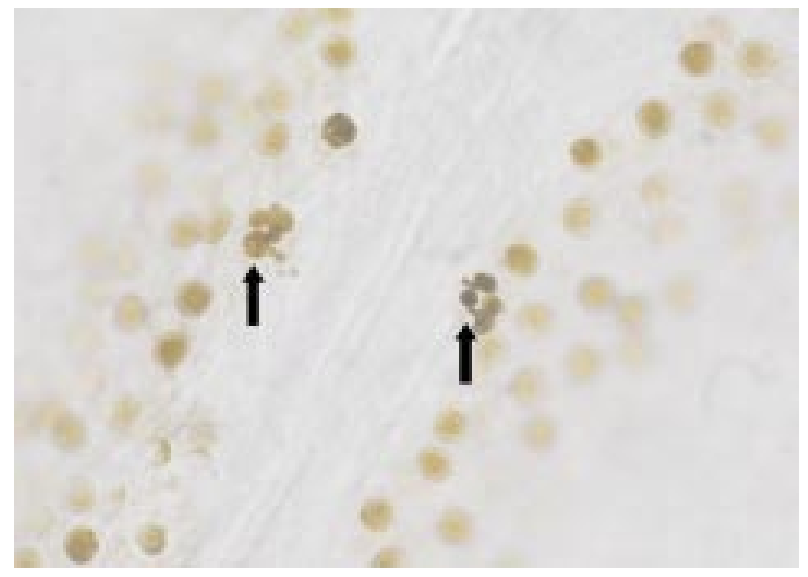

Figure 3 TUNEL positive ECs exhibiting nuclear fragmentation typical of apoptosis ( $\times 20$ magnification).

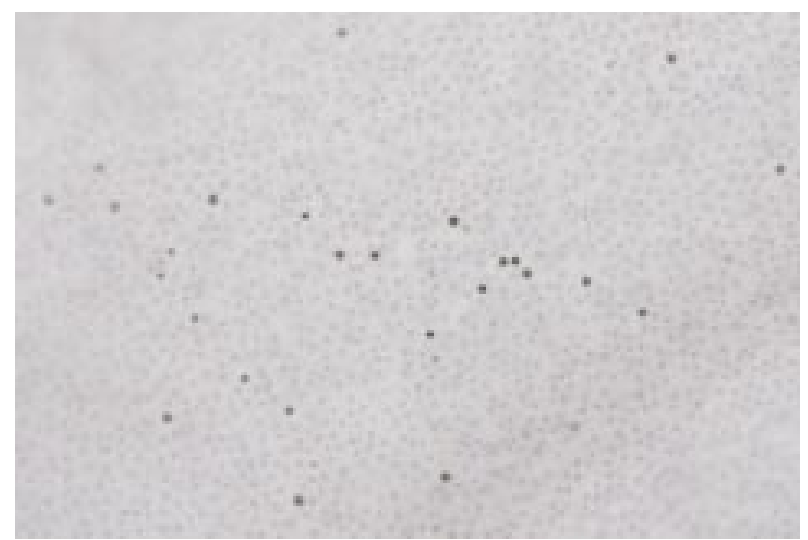

Figure 4 Rare TUNEL positive ECs disseminated within a non-stored cornea having a high cell density and displaying very few folds. Counterstaining of nuclei with haematoxylin $(\times 10$ magnification).

cornea: corneas were dehydrated for 10 minutes in $70 \%$ ethanol, 10 minutes in absolute ethanol, and 10 minutes in pure xylene. Four radial incisions were performed on the dehydrated corneas in order to allow permanent flat mounting of whole corneas using Eukitt mounting resin (O Kindler, Freiburg, Germany) (Fig 1). As with trypan blue staining, the analyser calculated the percentage of TUNEL positive cells as previously described.

Positive control consisted of apoptosis induction by staurosporine (Roche Diagnostics, Meyand, France). We used a standard concentration of $1 \mu \mathrm{M}$ staurosporine in Inosol and an increasing time of incubation (1,3, 8, 12, 18, and 24 hours). At the end of incubation, the endothelium was assessed as previously described by trypan blue staining and then fixed for TUNEL assay.

\section{Statistical analysis}

The relation between percentages of TUNEL positive ECs and donor sex was studied using the Mann-Whitney test. Correlations between TUNEL and trypan rates and donor age, PM time, storage time, initial and final EC density, and percentage of cell loss (final density minus initial density/initial density) were studied using the Spearman test. For the corneas that underwent two counts, we compared the mean percentages of trypan and TUNEL positive cells in two groups: one that showed low cell loss (0-9\%) during storage, and a second where cell loss was $10 \%$ or more. The $10 \%$ cell loss rate was chosen because it is the threshold beyond which, in some European banks, corneas are not delivered for grafting after

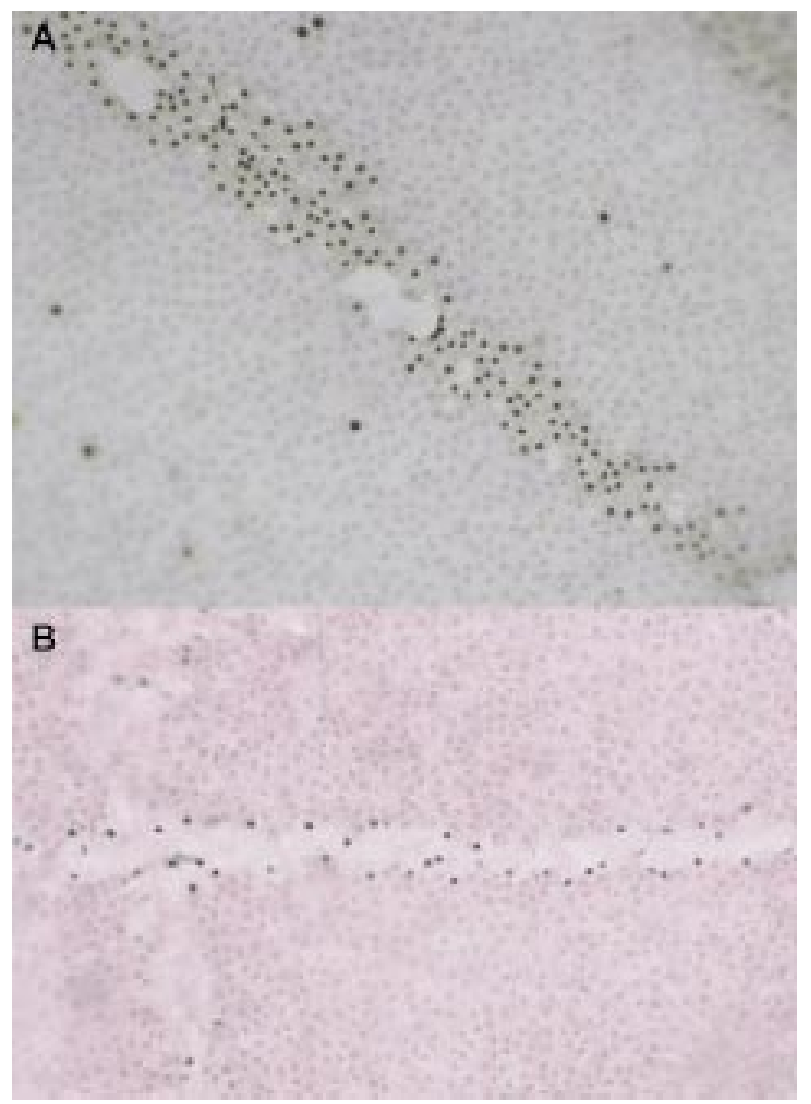

Figure 5 Corneal fold caused by organ culture and covered by TUNEL positive cells (A). Compare this fold with another fold that has already shed its central cells and whose cells on the fold edges are TUNEL positive. (B) Counterstaining of nuclei with haematoxylin ( $\times 10$ magnification).

2-3 weeks of organ culture. ' Statistical analysis was performed using the Statistical Package for Social Science (sPSs), with a p value below 0.05 regarded as significant.

\section{RESULTS}

Mean percentage cell death at the end of storage, assessed by the trypan blue technique, was $1.47 \%$ (SD 2.63, range 0.03-12). The in situ TUNEL technique on flat mounted corneas allowed detection, quantification, and localisation of positive cells in all corneas studied. The mean percentage of TUNEL stained ECs was $12.7 \%$ (SD 16.4, range 0.6-65.5). Using double labelling, the ECs stained using trypan blue (Fig 2A) were always less numerous than those marked by the TUNEL (Fig 2B). For each cornea, TUNEL percentage was higher than trypan percentage, while the TUNEL/trypan ratio ranged from 1.6-124.8 (mean 18.8, SD 25.7). There was a strong correlation between the percentage of trypan blue stained cells and the percentage of TUNEL positive cells ( $r=$ $0.7, \mathrm{p}<0.01$ ).

Only a few TUNEL positive cells also showed a feature typical of apoptosis: a completely fragmented nucleus (Fig 3). TUNEL labelling was never found in negative controls. Positive controls after incubation with staurosporine for 1, 3, 8, 12, 18, and 24 hours displayed an increasing percentage of TUNEL positive cells of $8.4,7.7,20.4,13.9,18$, and $26.5 \%$ respectively, with the same staining pattern as in non-induced corneas, including only a few cells showing fragmented nuclei. In the three non-stored corneas, the percentage of trypan positive cells was $0.1,0.25$, and $0.4 \%$, and the percentage of TUNEL positive cells was $0.6 \%, 0.6 \%$, and $3 \%$ respectively for 6,19 , and 42 hour periods between donor death and corneal harvesting. Of these corneas, positive cells were generally isolated within an endothelial 


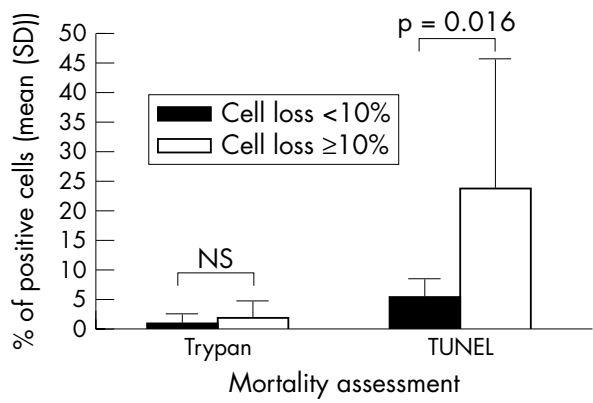

Figure 6 Comparisons of the two mortality rates, using trypan blue and the TUNEL technique in the two groups of corneas with $\mathrm{EC}$ loss $<10 \%$ (range 1.5-6.6, $\mathrm{n}=7$ ) and $\geqslant 10 \%$ (range 10.1-36.5, $\mathrm{n}=$ 12). There was a significant difference in the mean percentage of TUNEL positive cells $(5.5 \%$ (SD 2.7) v $23.5 \%(S D 22), p=0.016)$ but not in the mean percentage of trypan positive $(1.1 \%$ (SD 1.4) $\mathrm{v}$ $1.8 \%(\mathrm{SD} 2.8), \mathrm{p}=0.558)$.

mosaic with few folds (Fig 4). In all stored corneas, and particularly for those with numerous folds, TUNEL positive cells were mostly located either all over the corneal folds (crests and valleys) (Fig 5A) or at their periphery, when the cells located on the crests of the folds had desquamated (Fig 5B).

The percentage of trypan positive cells correlated with none of the parameters related to donors or storage. No significant relation was found between the percentage of TUNEL positive cells and donor sex, donor age, initial cell density, postmortem time, and storage time. However, TUNEL percentage was correlated negatively with final cell density $(r=-0.47, \mathrm{p}<0.005)$ and positively with percentage cell loss $(r=+0.46, \mathrm{p}<0.05)$.

For the 19 corneas that were counted at the start and end of organ culture, EC density ranged at the start of storage from 2581 to 1300 cells $/ \mathrm{mm}^{2}$ (mean 1834, SD 391) and at the end of storage from 2255 to 960 cells $/ \mathrm{mm}^{2}$ (mean 1579, SD 41 1), with a cell loss range of $1.5-36.4 \%$ (mean 14.3, SD 10). For the seven corneas whose mean storage period was 23 days (SD 9), cell loss during banking was very low (1.5-6.6\%). For the 12 others, EC loss was high (range 10.1-36.5\%), with comparable storage duration of 22 days ( SD 8) $(\mathrm{p}=0.743)$. The mean percentage of TUNEL positive cells was higher in the high EC loss group than in low EC loss group (respectively 23.5\% (SD 22) $v$ $5.5 \%$ (SD 2.7), $\mathrm{p}=0.016$ ) while the percentage of trypan stained cells was not statistically different in both groups (respectively 1.8\% (SD 2.8) $v 1.1 \%$ (SD 1.4), $\mathrm{p}=0.558$ ) (Fig 6).

At the end of organ culture, 14 corneas (45\%) had cell density greater than 2000 cells $/ \mathrm{mm}^{2}$ and would thus have been suitable for grafting. Of these corneas, the percentage of trypan positive cells was higher than $2 \%$ in one cornea (mean $0.8 \%$, SD 1.0 , range $0.1-4.1$ ) whereas the percentage of TUNEL positive cells was higher than $2 \%$ in 11 corneas (mean $4.4 \%$, SD 2.7, range 0.6-9.8)

\section{DISCUSSION}

Our study shows that the technique of vital staining with trypan blue greatly underestimates the number of non-viable cells in human corneal endothelium after organ culture. The number of ECs irreversibly engaged in apoptosis and identified by the in situ TUNEL technique always exceeds the number of cells identified by trypan blue. This is true even of corneas showing a final cell density compatible with cornea delivery. Albon et $a l^{10}$ showed that the endothelium adapted TUNEL technique allowed highly specific identification and quantification of apoptotic ECs during organ culture. In our study, the presence of TUNEL positive ECs after cornea incubation with staurosporine, which is a broad spectrum kinase inhibitor and a powerful chemical inducer of apoptosis, is a further argument to validate the technique.
In our study, as in Albon's, ${ }^{10}$ TUNEL positive ECs showed only rarely the classic morphological modifications of apoptosis, such as nuclear fragmentation, chromatin condensation, and apoptosome formation, ${ }^{23}$ and whether apoptosis was spontaneous or staurosporine induced. Komuro et $\mathrm{al}^{16}$ studied the role of apoptosis compared with necrosis in the mortality of the three types of human corneal cell stored at $+4^{\circ} \mathrm{C}$, by the cross section TUNEL technique and by the study of microphotographs obtained using transmission electron microscopy (TEM). Komuro et al highlighted ultrastructural morphological changes characteristic of apoptosis in the stroma keratocytes, but not in the epithelium or endothelium. We were thus not surprised, when using an optical microscope, to find a small number of ECs showing morphological changes deemed characteristic of apoptosis. In addition, the end result of apoptosis is the elimination of non-functional cells. Within solid tissues, this elimination requires execution of all phases of apoptosis, through to total fragmentation of the apoptotic cell body, to allow phagocytosis by the tissular macrophages or adjacent cells. Such complete destruction is perhaps not required for cells that need only to shed their original tissue. Desjardins ${ }^{24}$ described another type of apoptotic morphology, in the single layer adhering tissues, related to rapid shedding of cells, which modifies the classic sequence of the morphological stages of apoptosis. This unusual morphology of apoptosis was described on cultures of colon epithelial cells, with states successively comprising "preapoptotic, swelling, rounding and floating cells." Estil et al ${ }^{25}$ recently described an apoptotic morphology as "non-classic," for the superficial epithelial cells of the cornea after microtraumatisms induced by the repeated fitting and removal of contact lenses, a situation where morphological changes have no time to occur due to the rapid elimination of apoptotic cells by shedding. We therefore find it plausible that ECs are shed from the cornea during organ culture by "non-classic apoptosis."

Like Albon, ${ }^{10}$ we noted that apoptosis remained low when corneas were not stored and/or had few folds and predominated in the folds caused by organ culture. Crewe, ${ }^{11}$ in his study using a confocal microscope, found far more limited endothelial apoptosis. However, this author's observation regards corneal fragments and particularly zones where the endothelial mosaic was intact. Our study, like Albon's, is on whole corneas, allowing easy observation of the entire endothelium and the fold zones in particular. Indeed our observation agrees with daily practice in cornea banks, where endothelial mortality is identified by trypan blue preferentially in the region of the folds. This mortality agrees with the lack of expression of heat shock proteins 27, 60, 70, and 90, which are potentially involved in protecting against cell death by apoptosis, which is observed in the ECs of the corneal folds. ${ }^{26}$ The loss of adhesion between the cells, or between the cells and the extracellular matrix, is an event capable of triggering the apoptotic process within adhering cell lines. ${ }^{27}$ In his study on apoptosis in Fuchs' dystrophy, Borderie ${ }^{28}$ raises the possibility that changes to the Descemet membrane trigger EC death by apoptosis. It is likely that the changes in cell Descemet and cell-cell adhesion observed in the corneal folds cause losses of survival signs and/or trigger apoptotic stimuli.

We found no influence of donor age on apoptotic cell rates, like Albon et al..$^{10}$ This agrees with clinical observation, which, given equal storage durations, notes that corneas from old donors do not lose more cells than those from younger donors. ${ }^{29}$ But it was interesting to note that the percentage of TUNEL positive cells was higher for corneas with low cell density at the end of storage, and for corneas with high cell loss, while the percentage was the same with trypan blue staining. The principle of trypan blue staining is that cells with an intact plasmic membrane do not take up dye-that is, it reveals only cells that have substantially altered membrane permeability. ${ }^{30}$ This technique does not prejudge the initial mechanism of type of cell death, be it necrosis or apoptosis. It is, however, certain 
that cell membrane integrity is only affected at a very late stage in apoptosis in some cell types, ${ }^{18-21}$ but this remains to be demonstrated within the human endothelium. Trypan blue therefore visibly detects only necrotic cells the membrane of which is permeable, and could only highlight apoptotic cells at a very late stage, when they potentially display membrane lesions. It was therefore logically observed that trypan blue staining substantially underestimates the number of non-viable apoptotic cells. Likewise, the lack of correlation between the percentage of trypan blue positive ECs and cell loss or end of storage density might be explained by rapid shedding of apoptotic cells, meaning that these cells do not "have time" to be identified by vital staining. This is particularly well demonstrated in the fold zones, where one frequently observes a central cell free zone and a peripheral fold zone bordered with TUNEL positive and trypan negative ECs which are in the process of shedding. As the TUNEL technique identifies apoptosis once the DNA starts to fragment, a phenomenon relatively extended in time, higher positive cell percentages were thus logically observed in the group of corneas that had lost more cells during storage. These observations, coupled with further manipulations caused by trypan blue staining, and its relative lack of visibility as a result of a frequently low contrast, have prompted European cornea banks to replace this technique with an overall assessment of endothelial quality. ${ }^{9}$ Wilhelm et al showed that trypan blue staining substantially underestimates the number of nonfunctional ECs, ${ }^{31}$ although there was no suggestion the cells were apoptotic. In our view this "instantaneous" technique, which does not prejudge overall endothelial viability, should rather be used as a method to visualise areas of dead cells and not to calculate actual mortality. In our series, the majority of corneas showing an acceptable end of storage EC density presented trypan tested mortality rate of less than $2 \%$, whereas in most corneas the number of cells irreversibly engaged in apoptosis considerably exceeded this value. This explains, at least partly, the high cell loss observed in the first days after penetrating keratoplasty, even in cases where the recipient showed high EC density. ${ }^{32} 33$

In conclusion, as Darzynkiewicz et $a l^{34}$ emphasised, assessment of cell death dynamics based on a single instantaneous measure is random, especially when the technique used has only a short time window of positivity. Because the TUNEL technique offers a larger positivity window in this respect than trypan blue staining, it better reflects the dynamics of cell death within the endothelium. We thus believe that it is useful for the experimental quantification of cell death during human cornea storage procedures, and that it could prove particularly useful for studying new storage media without fetal calf serum or which contain anti-apoptotic agents.

\section{ACKNOWLEDGEMENTS}

Presented in part at the annual meeting of the Association for Research in Vision and Ophthalmology, Fort Lauderdale, May 1999, and at the European Eye Bank Association meeting in Zagreb, January 1999.

Supported by grants from the Fondation de l'Avenir pour la Recherche Médicale Appliquée (ET9-284) and the Projet Avenir of the Rhône-Alpes Region (99006800).

We wish to thank A Tullo and AEA Ridgway of the Royal Eye Hospital in Manchester, and M Boulton and J Albon, for their precious advice and warm welcome.

\section{Authors' affiliations}

P Gain, G Thuret, L Campos, Cell Death and Neoplasia Laboratory, University of Saint-Etienne, France

C Chiquet, C Burillon, Department of Ophthalmology, Edouard Herriot Hospital, University of Lyon, France

J M Dumollard, J F Mosnier, Department of Pathology, Bellevue Hospital, University of Saint-Etienne, France

B Delbosc, P Hervé, French Blood Centre, Corneal Bank, Besançon, France

\section{REFERENCES}

1 Frueh BE, Bohnke M. Corneal grafting of donor tissue preserved for longer than 4 weeks in organ-culture medium. Cornea 1995; 14:463-6.

2 Means TL, Geroski DH, Hadley A, et al. Viability of human corneal endothelium following Optisol-GS storage. Arch Ophthalmol 1995: 113:805-9.

3 Armitage WJ, Easty DL. Factors influencing the suitability of organ-cultured corneas for transplantation. Invest Ophthalmol Vis Sci 1997;38:16-24.

4 Chu W, Dahl P, O'Neill M. Benefits of specular microscopy in evaluating eye donors aged 66 and older. Cornea 1995;14:568-70, 634.

5 Mattern RM, Heck EL, Cavanagh HD. The impact on tissue utilization of screening donor corneas by specular microscopy at the University of Texas Southwestern Medical Center. Cornea 1995;14:562-7.

6 Moyes AL, Holland EJ, Palmon FE, et al. Tissue utilization at the Minnesota Lions' Eye Bank. Cornea 1995;14:571-7.

7 Wiffen SJ, Nelson LR, Ali AF, et al. Morphologic assessment of corneal endothelium by specular microscopy in evaluation of donor corneas for transplantation. Cornea 1995;14:554-61.

8 Maas-Reijs J, Pels E, Tullo AB. Eye banking in Europe 1991-1995. Acta Ophthalmol Scand 1997;75:541-3.

9 European Eye Bank Association Directory. 9th ed. 2001.

10 Albon J, Tullo AB, Aktar S, et al. Apoptosis in the endothelium of human corneas for transplantation. Invest Ophthalmol Vis Sci 2000:41:2887-93.

11 Crewe JM, Armitage WJ. Integrity of epithelium and endothelium in organ-cultured human corneas. Invest Ophthalmol Vis Sci 2001;42:1757-61

12 Gavrieli $Y$, Sherman Y, Ben-Sasson SA. Identification of programmed cell death in situ via specific labeling of nuclear DNA fragmentation. $J$ Cell Biol 1992;119:493-501.

13 Grasl-Kraupp B, Ruttkay-Nedecky B, Koudelka H, et al. In situ detection of fragmented DNA (TUNEL assay) fails to discriminate among apoptosis, necrosis, and autolytic cell death: a cautionary note. Hepatology 1995;21:1465-8.

14 Charriaut-Marlangue $C$, Ben-Ari Y. A cautionary note on the use of the TUNEL stain to determine apoptosis. Neuroreport 1995; 7:61-4.

15 Yasuda M, Umemura S, Osamura RY, et al. Apoptotic cells in the human endometrium and placental villi: piffalls in applying the TUNEL method. Arch Histol Cytol 1995;58: 185-90.

16 Komuro A, Hodge DO, Gores GJ, et al. Cell death during corneal storage at 4 degrees C. Invest Ophthalmol Vis Sci 1999;40:2827-32.

17 Borderie VM, Baudrimont $M$, Lopez $M$, et al. Evaluation of the deswelling period in dextran-containing medium after corneal organ culture. Cornea 1997; 16:215-23.

18 Mower DA Jr, Peckham DW, Illera VA, et al. Decreased membrane phospholipid packing and decreased cell size precede DNA cleavage in mature mouse B cell apoptosis. J Immunol 1994;152:4832-42.

19 Kroemer G, Petit $P$, Zamzami N, et al. The biochemistry of programmed cell death. Faseb J 1995;9:1277-87.

20 O'Brien MC, Healy SF Jr, Raney SR, et al. Discrimination of late apoptotic/necrotic cells (type III) by flow cytometry in solid tumors. Cytometry 1997;28:81-9.

21 Hong JR, Lin TL, Yang JY, et al. Dynamics of nontypical apoptotic morphological changes visualized by green fluorescent protein in living cells with infectious pancreatic necrosis virus infection. J Virol 1999:73:5056-63.

22 Gain $\mathbf{P}$, Thuret $G$, Chiquet $C$, et al. Automated analysis of organ cultured endothelium mosaic [ARVO abstract]. Invest Ophthalmol Vis Sci 2001;42:S277. Abstract no 1502

23 Kerr JF, Wyllie AH, Currie AR. Apoptosis: a basic biological phenomenon with wide-ranging implications in tissue kinetics. $\mathrm{Br} \mathrm{J}$ Cancer 1972;26:239-57.

24 Desjardins LM, MacManus JP. An adherent cell model to study different stages of apoptosis. Exp Cell Res 1995;216:380-7.

25 Estil S, Primo EJ, Wilson G. Apoptosis in shed human corneal cells. Invest Ophthalmol Vis Sci 2000;41:3360-4.

26 Gain $P$, Thuret $G$, Chiquet $C$, et al. In situ immunohistochemical study of $\mathrm{Bcl}-2$ and heat shock proteins in human corneal endothelial cells during corneal storage. Br J Ophthalmol 2001;85:996-1000.

27 Boudreau N, Sympson CJ, Werb Z, et al. Suppression of ICE and apoptosis in mammary epithelial cells by extracellular matrix. Science 1995;267:891-3.

28 Borderie VM, Baudrimont M, Vallee A, et al. Corneal endothelial cell apoptosis in patients with Fuchs' dystrophy. Invest Ophthalmol Vis Sci 2000;41:2501-5.

29 Borderie VM, Scheer S, Touzeau O, et al. Donor organ cultured corneal tissue selection before penetrating keratoplasty. Br J Ophthalmol 1998;82:382-8.

30 Stocker FW, King EH, Lucas DO, et al. A comparison of two different staining methods for evaluating corneal endothelial viability. Arch Ophthalmol 1966;76:833-5.

31 Wilhelm F, Melzig M, Gorscher T, et al. [Differential value of various vital stains of corneal endothelium.] Ophthalmologe 1995;92:496-8.

32 Obata H, Murao M, Miyata K, et al. [Corneal endothelial cell damage in penetrating keratoplasty.] Nippon Ganka Gakkai Zassh 1992;96:346-51.

33 Culbertson WW, Abbott RL, Forster RK. Endothelial cell loss in penetrating keratoplasty. Ophthalmology 1982;89:600-4.

34 Darzynkiewicz Z, Bedner E, Traganos F, et al. Critical aspects in the analysis of apoptosis and necrosis. Hum Cell 1998;11:3-12. 